\section{Documentos de trabajo/ Working paper series}

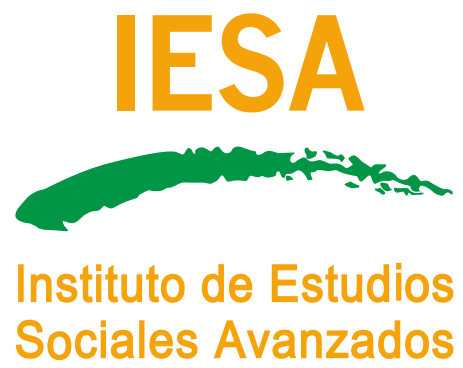

Sociales Avanzados

\title{
FARMERS' CONTRIBUTION TO \\ AGRICULTURAL SOCIAL CAPITAL: \\ EVIDENCE FROM SOUTHERN SPAIN
}

José A. Gómez-Limón

Department of Agricultural Economics, University of Córdoba, Córdoba, Spain

Esperanza Vera-Toscano

Instituto de Estudios Sociales Avanzados, Consejo Superior de Investigaciones

Científicas, Córdoba, Spain

Fernando E. Garrido-Fernández

Instituto de Estudios Sociales Avanzados, Consejo Superior de Investigaciones Científicas, Córdoba, Spain

October 2012 


\section{Farmers' contribution to agricultural social capital: Evidence from Southern Spain}

\section{Introduction}

In broad terms, sustainable development has been defined as a process whereby future generations receive as much capital per capita as -or more than- the present generation has available (WCED, 1987). Traditionally, this has included natural capital, physical or produced capital, and human capital (all durable production factors). Together they constitute the wealth of nations and form the basis of economic development and growth. However, these three types of capital only partially determine the process of economic development since they overlook the way in which economic actors interact within communities and organize themselves to produce demanded goods and services and also to increase the existing amount of the different types of capital. In this context, the concept of "social capital", which according to Grootaert (1998) refers to the complementary norms, values, attitudes and beliefs that govern interactions among people and institutions and predispose them to cooperation and mutual assistance, has gained much prominence during the last two decades as a new kind of capital that boosts economic growth and sustainable development (Coleman, 1988 and 1990; Putnam et al., 1993).

In this sense, there is also agreement about the relevance of social capital in the ability of rural communities to manage and respond to the economic, social and environmental pressures in an attempt to guarantee sustainable development (Mathijs, 2003; Jordan et al., 2010; Munasib and Jordan, 2011). Accordingly, new empirical research has shown that rural communities endowed with a rich stock of social capital (social networks and norms and values associated with social relationships) are in a stronger position to resolve disputes, share useful information and implement successful development projects, whereas similar endowments of traditional production factors (natural, physical and human capital) do not necessarily lead to equivalent patterns of economic growth and development in other communities (Trigilia, 2001; Woodhouse, 2006; Nardone et al., 2010).

Social capital has thus become a major topic in the development literature, its importance in facilitating the development process being increasingly recognized. Nonetheless, much of the discussion about social capital is clouded by both the complexity of the concept, the analysis of which requires considering multiple dimensions (further details are provided in the next section) and also the fact that most of its components are intangible, which makes them difficult to observe or measure (Coleman, 1990; Putnam, 1995). These circumstances have resulted in most of the existing empirical studies aimed at measuring the stock of this capital relying on partial approaches, only considering specific dimensions of social capital for which accurate data are available (such as formal associations). Hence, a more integral and multidimensional measure of the concept of social capital based on a reliable data gathering process would certainly add to the existing literature (Durlauf and Fafchamps, 2006). 
Furthermore, it is also worth pointing out that while social capital can be operationally defined and measured at different levels of analysis, including individuals (Belliveau et al., 1996 and Brehm and Rahn, 1997), organizations/firms (Nahapiet and Ghoshal, 1998 and Yli-Renko et al., 2001) and communities/societies, most of the previous literature has focused on the latter approach, namely measuring the stock of social capital at state or county level (see Putnam, 1993, 1995, 2000; Knack and Keefer, 1997; La Porta et al., 1997; Guiso et al., 2004; Rupasingha et al., 2006 and Sabatini, 2008 and 2009a, among others). Research focusing on the accumulation of social capital and its different components at individual farmer level are scarce (Adesina and Baidu-Forson, 1995; Uphoff and Wijayaratna, 2000; Monge et al., 2008) and more evidence is required to fully understand the role of social capital in agricultural development.

Within this framework, the purpose of this research is two-fold. First, we hope to design a practical method for assessing farmers' contribution to agricultural social capital using indicators that would cover all the dimensions and sub-dimensions of social capital and also permit the creation of a composite indicator for the agricultural social capital accumulated at farmer level. This methodological approach is applied to farmers in Andalusia (southern Spain) as an illustrative case study. Second, using the values obtained for the foregoing index, we identify factors that influence the production of social capital at farmer level using an array of individual and regional features that are theoretically important determinants of social capital. Consequently, the results will determine how scarce social capital is at farmer level and which factors are behind that scarcity. This information is expected to be useful for agricultural policymakers when it comes to designing successful strategies aimed at improving the stock of social capital as a key ingredient to achieve sustainable development in the farming sector.

Several features distinguish this research from previous work found in the literature aimed at overcoming some of the difficulties mentioned above. First, the research is based on a large quantitative dataset of Andalusian farmers, which includes an extensive set of variables representing different dimensions and sub-dimensions of the concept of social capital and a large set of control variables related to individual socio-demographic and socioeconomic characteristics. These data have been gathered by implementing an ad hoc survey designed to obtain reliable data. Second, in this case all dimensions and sub-dimensions of the social capital accumulated at farmer level are analyzed by building up a composite indicator which has never been used previously. Third, the research primarily focuses on social capital formation at farmer level, but some authors argue that aggregate social capital at sector or community level is formed from the different levels of social capital possessed by these individual producers (Glaeser et al., 2000). Therefore, the results of this paper can be expected to further contribute to the research on the effects of social capital at county/regional level.

The remainder of the paper is structured as follows. Section 2 summarizes the theoretical background of the concept of social capital (dimensions and sub-dimensions of the concept) and its effects on agricultural development. Based on this theoretical framework, Section 3 is devoted to detailing the approach taken in this paper to measuring the different components of social capital at farmer level. Section 4 presents the case study (Andalusian farming sector) and explains the process 
followed for primary data gathering. Section 5 discusses the procedure to build the composite indicator proposed for measuring farmers' contribution to agricultural social capital and Section 6 provides the results, both at farmer and sector level. Finally, Section 7 concludes.

\section{Social capital and farming}

\subsection{Social capital as a multidimensional concept}

In order to understand the configuration of social capital among farmers, there must be a coherent model of how it forms. This paper adopts the multidimensional approach to the concept by Putnam (1995) and integrates various facets to define social capital in three different dimensions, namely structural, cognitive and relational social capital, as proposed by Nahapiet and Ghoshal (1998) and Uphoff and Wijayaratna (2000). The main differences between the three dimensions are as follows. Structural forms of social capital, which refer to the interpersonal formation of linkages between individuals or groups, facilitate cooperation by lowering transaction costs and accumulating social learning. Alternatively, cognitive forms of social capital, including attributes such as a joint code or a shared paradigm that facilitates a common understanding of collective goals and proper ways of acting in a social system (Ostrom, 2000), even in the absence of specific links and relations between individual members of the group, predispose people to cooperate (Uphoff, 1999, p. 218). In contrast, the relational dimension of social capital, described as the type of (not necessarily longlasting) personal relations people have built up between them through a number of interactions (Granovetter, 1992) result in cooperation being expected. For these reasons, we believe this approach to the concept of social capital is highly inclusive. Later in this section, we justify theoretically how the different attributes of each of these dimensions facilitate the combination and exchange of resources within the agricultural sector. Figure 1 graphically represents the different dimensions and sub-dimensions of social capital, which are then discussed below.

\section{FIGURE 1 AROUND HERE}

The structural dimension of social capital is comprised of social interactions. This dimension explains how individuals can obtain certain advantages by using personal contacts within the social structure of interactions. That is, people can use their personal contacts to get jobs, obtain information, or access specific resources. The literature has made a key segregation within the structural dimension, distinguishing between what is referred to as bonding and bridging social capital (Putnam, 2000; Narayan, 1999). Bonding social capital refers to the social capital generated through interaction between members of a relatively homogenous group (family or close friends), while bridging social capital refers to the social capital generated and shared through interconnections between heterogeneous groups (neighbors or other acquaintances). Another component of the structural dimension is defined as linking social capital, which describes ties connecting individuals, or the groups they belong to, to people or groups in a position of political or financial power. For instance, civil society organizations allow citizens to come into contact with 
institutions to carry out support activities through collective action. According to Evans (1996), such linkages allow groups to access resources, ideas and information from institutions of power, enabling group members to 'scale up' micro-level social capital and social action to a politically and economically effective level. Lastly, the structural dimension also comprises corporate social capital, which is formed by professional associations (farmers' unions or agricultural cooperatives) that pursue the special interests of its members (Sabatini, 2009). One key feature of the structural forms of social capital is that they seem relatively external and objectified.

In contrast, the relational dimension of social capital describes the type of personal relations people have built up between them through a number of interactions (Granovetter, 1992). The key attributes of this dimension will include trust and trustworthiness (Fukuyama, 1995; Putnam, 1993), norms and social sanctions (Coleman, 1990; Putnam, 1995) and reciprocity (Coleman, 1990; Granovetter, 1985; Nyhan Jones and Woolcock, 2007).

Thus, while trust is an attribute of a relationship, trustworthiness is an attribute of an individual actor involved in the relationship (Barney and Hansen, 1994). Trust can act as a control mechanism for embedded relationships (Uzzi, 1996), since it can encourage joint efforts (e.g., Gambetta, 1988), whereas a lack of mutual trust is certain to impact negatively on development (Arrow, 1974, p. 26). Likewise, a trustworthy actor (one who can be trusted by other actors) is likely to gain other actors' support for achieving goals to an extent that would not be possible in a situation where trust did not exist. For analytical purposes, and following Sabatini (2009a), different levels of trust have been identified in this research, namely knowledge-based trust as given by the confidence in well-known people, generalized social trust (trust towards unknown people) and trust in public services as a result of using and having access to them. This paper specifically considers the latter attribute of trust in public services due to focusing on the importance of individual social capital for regional sustainable development. Pioneer insights from Kumlin and Rothstein (2005) reveal positive and significant correlation between trust in public services and social trust and development. It will therefore be interesting to see how both attributes contribute to the accumulation of social capital at individual level. The analysis also includes "Subjective safety", understood as the subjective perception that the local community is a safe place to live.

Equally, as argued by Coleman (1990), a norm exists when it represents a degree of consensus in the social system, becoming a powerful form of social capital as it may give individuals the confidence to invest in collective or group activities, knowing that others will do so as well as a result of interaction. Norms and social sanctions are effectively expectations that bind (Kramer and Goldman, 1995), as is the case with general reciprocity, understood as the combination of short-term altruism and long-term self-interest (Taylor, 1982), or what de Tocqueville (1969) called 'self interest rightly understood'. The individual provides a service to others or acts for the benefit of others at a personal cost, but in the general expectation that this kindness will be returned at some undefined time in the future in case of need. In a community where reciprocity is strong, people care about each other's interests. As indicated by Nyhan Jones and Woolcock (2007), the usefulness of this element stems from the fact that in the vast majority of settings, cooperation for development is possible only if a significant amount of social capital of this kind is available in the community. 
Finally, the third dimension of social capital labeled as the cognitive dimension refers to resources that have a joint code or a shared paradigm that facilitates a common understanding of collective goals and proper ways of acting in a social system (Ostrom, 2000), in the absence of specific links and relations between individual members of the group. Common understanding is appropriable by the collectivity as a resource (Portes and Sensenbrenner, 1993), capturing the essence of what Coleman (1990, p. 315) described as 'the public good aspect of social capital'. A key feature of this dimension is the level of civicness among individuals in the community. That is, people's propensity to keep themselves informed about public affairs. The claim for civicness is that well-informed citizens have a better knowledge of public affairs and greater confidence in their ability to influence public choices. Therefore, they are more likely to be involved in collective action and public life (Putnam, 2000). In essence, this cognitive dimension also refers to the compatibility of individuals' values with community values; its forms rationalize cooperative behavior and make it respectable. Thus, we further consider a second attribute of this dimension as the perceived degree of community cohesiveness, since a certain degree of cohesiveness is always desirable for ensuring sustainable development. Coleman (1990, p. 303) showed how certain values collectively held by society's individuals can be a kind of social capital that benefits the society as a whole.

\subsection{Social capital and sustainable development: Evidence from farming}

Traditionally, the importance of specific associations such as cooperatives or farmers unions when structuring the agricultural sector has been widely studied in the agricultural economics and sociology literature as the most distinctive feature and a very meaningful expression of social capital within the sector (Just, 1990; Moyano, 1995). In our attempt to properly understand and utilize the concept of social capital in the farming community, this section analytically emphasizes the roles that the social relationships among farmers may play in the sustainable development of rural regions.

Thus, social relationships/networks may affect the economic sustainability of farmers by influencing farming practices and their propensity to adopt newer technologies via the supply of information through these networks. Farmers can then learn new techniques and acquire know-how, obtain informal training from others who have already adopted such practices and even obtain official assistance to implement various practices. In addition, the role of networks in providing information about employment and market opportunities has been greatly documented (Fafchamps and Minten, 1998; Granovetter, 1995; Montgomery, 1991; Rauch and Casella, 2001). In this sense, social capital may also indirectly impact agricultural productivity and economic sustainability, as well as regional social sustainability, since it affects the quantity of labor available either through the immediate and extended family or the social relationships available to the individual. This is particularly important following the increase in rural-urban migration, which may create restrictions in the supply of rural farm labor.

More broadly speaking, regional social sustainability may also be achieved by the role that farmers may play in the network of associations in rural areas of a non-agricultural nature. These types of associations play an important role in the social structure of territories and further contribute to the defense of cultural and natural heritage, social cohesion, the promotion of 
entrepreneurial initiatives and to the construction of a social identity (cultural, civic, religious, developmental, women's and youth associations, environmental groups, etc.), as has been proved by Jordan et al. (2010).

Lastly, social capital among farmers, as built through community involvement, may also enhance social responsibility by promoting the use of sustainable agricultural farming practices and thereby contributing to environmental sustainable development. In this sense the works by Mathijs (2003) and Munasib and Jordan (2011) are worth to be quoted, as they evidence how social capital has a positive effect on the environmental awareness of farmers, and thus on the adoption of new environmental-friendly agricultural practices.

In short, several authors have highlighted the importance of associations in rural development policies from the perspective of "social capital", since associations emerge as a result of trust between individuals and are the basis for greater trust and new collective efforts to undertake projects that benefit the whole community (Putnam, 1993). The role of associations as intermediaries in the implementation of public policies is highly valued. Social capital is, therefore, linked to the quality of the existing associative environment at local level and has a significant influence on the dynamics of development in rural areas and ultimately on the viability of rural communities and their social cohesion, where farmers are key-dwellers.

The above evidence suggests the importance of properly measuring farming social capital to better understand the economic, social and environmental sustainability of rural territories and once more justifies its theoretical and practical utility.

\section{Social capital as an intangible: measurement approaches}

The rationale behind this research is that the accumulation of social capital among farmers is likely to have an impact on the agricultural development and sustainability of rural regions. This is the motivation behind trying to learn more about farmers' contribution to agricultural social capital, a multidimensional concept that has already been widely discussed in the literature. Nonetheless, it is evident that social capital as a resource is elusive and cannot be seen or touched. Hence, it can only be measured by making reference to those features of human behavior and relationships that this concept is associated to, such as the process which results in the accumulation of social capital. As discussed in the theoretical background section, there is general agreement that this process includes features of society such as associations, trust, tolerance, civicness, generalized reciprocity, social sanctions and community cohesiveness. Thus, in order to capture the intangible concept of social capital, a functional measurement method should focus on direct indicators of each of those features. This arrangement is one way of overcoming the conceptual plainness of this kind of immaterial resource and makes it possible to focus the research on the specific components of social capital, which figure prominently in the context of agricultural and regional policies for sustainable development.

The idea that the empirical evaluation of farmers' contribution to agricultural social capital should be based on the foregoing multiple dimensions (using either composite indicators or alternative quantitative approaches) has been gaining ground as a prerequisite for the adequate 
design, implementation and monitoring of agricultural policies aimed at a more sustainable farming sector. This approach to the concept has the advantage that it can be developed in operational terms by utilizing systems of indicators that embrace all these dimensions. However, the quantification of farmers' contribution to agricultural social capital by means of indicators continues to entail operational problems. The greatest difficulty involves jointly interpreting the whole set of indicators required for such analyses, which is an obstacle when it comes to using them as a practical public decision-support tool. Attempts have been made to deal with this problem by applying various methods to aggregate these combinations of multidimensional indicators into indices or composite indicators, like the contributions of Putnam et al. (1993), Narayan (1999), Onyx and Bullen (2000), Grootaert et al. (2002), Rupashinga et al. (2006), Woodhouse (2006), Nyhan Jones and Woolcock (2007) and Sabatini (2009a, 2009b).

It is possible to draw certain conclusions from the existing literature, most importantly that composite indicators of farming social capital (quantitatively measured) are useful as a means of summarizing the information provided by base indicators in an overall judgment or evaluation of farmers' contribution to agricultural social capital and for developing an assessment that permits individual farmers or farming districts to be ranked from best to worst, taking into account a whole set of features. In sum, building transparent composite indicators provides an opportunity to identify which aspects of agricultural social capital are relevant in practice.

From a methodological point of view, the literature also shows some guidance regarding the construction of composite indicators to build social capital indices. In this sense, is worth pointing out that the first stage in the development of the methodology for our research was to select a plan of indicators for the evaluation of farmers' contribution to agricultural social capital that would cover all the dimensions (structural, relational and cognitive) and sub-dimensions discussed previously. This selection of indicators was based on the sound theoretical framework discussed in Section 2.1, which we believe is a highly inclusive approach to the concept. Thus, we began by constructing a general catalogue of indicators of agricultural social capital for each of the dimensions and sub-dimensions considered. This catalogue was based on an extensive review of the literature, from which we took the indicators utilized in previous studies carried out both by institutions (Social Capital Initiative or the World Bank) and by individual researchers (Grootaert et al., 2002; Sabatini, 2009a and 2009b and Woodhouse, 2006, among others). Second, we selected the better grounded proxies of the different components of social capital to measure them at farmer level. Third, we adapted these proxies or indicators to our particular case study and validated the resulting questionnaire using a pilot survey, which tested that the respondents correctly understood the questions and how accurately the indicators measured those features. Employing this procedure, we finally obtained a hierarchy that comprised 52 indicators (17 for structural social capital, 19 for relational social capital and 16 for cognitive social capital), as shown in Table A1 in the Appendix. 


\section{Case study and data collection}

\subsection{Farming sector in Andalusia}

The empirical research has been carried out in the Autonomous Region of Andalusia (Southern Spain) which has a surface area of 87.5 million $\mathrm{km}^{2}$ and a population of 7.6 million inhabitants, accounting for $17.3 \%$ of the Spanish territory and $17.8 \%$ of its population. Agriculture is the most important land use in Andalusia, occupying $58 \%$ of the regional territory, $45 \%$ being devoted to crops and $13 \%$ to pastures (MARM, 2010). There is a wide variety of agricultural systems ranging from intensive, greenhouse crop production in coastal areas to traditional inland Mediterranean olive groves, cereal farms and vineyards. Meanwhile, mountain areas are occupied by more extensive and marginal systems, which are mainly devoted to animal production and olive growing.

The Final Agricultural Production (FPA) of the Andalusian farming sector amounted to $€ M$ 10,125 in 2010, one quarter of Spanish FPA (AEA, 2012). This production generated Gross Value Added (GVA) of $€ M 5,574$ that year, accounting for $4.2 \%$ of GVA for the region as a whole, a percentage that is more than twice the figure for Spain (1.9\%) and more than three times the figure for the European Union (1.2\%) (EU-DG Agri, 2011). Moreover, it is also worth pointing out that the economic relevance of farming in Andalusia goes beyond these figures, as agriculture also plays a key role as a provider of raw materials for the regional agri-food industry, the largest industrial sector in Andalusia, which generates $34 \%$ of regional exports.

The agricultural sector in Andalusia is also relevant from a social point of view, employing around 240,000 people (6.5\% of the regional labor force in 2010) (CAP, 2012a). These figures also reveal that farming is more important to Andalusia than Spain as a whole (3.8\% of the working population engaged in agriculture) and the European Union (4.7\%) (EU-DG Agri, 2011).

The farming sector in Andalusia is not only relatively large, but also widespread. Farms operate in all the municipalities in Andalusia, generating employment and fixing population right across the region. In fact, it remains the main source of income in half of the municipalities of Andalusia, especially the most depopulated and those located in marginal inner rural areas (CAP, 2012b). In addition, more than $50 \%$ of Andalusian people consider the agricultural sector one of the main driving forces behind regional development, while $73 \%$ say they are either highly or quite concerned about issues related to agriculture (IESA-CSIC, 2009).

In view of the long agricultural history of this region and the importance given to farming as a provider of private and public goods and services to society so as to ensure sustainable rural development, it seems very appropriate to use the Andalusian farming sector as the case study for the purpose of this research.

\subsection{Data collection}

In order to feed numerical values into the calculation of the social capital indicators defined for the study area at farmer level, a specific questionnaire was designed and tested. The questionnaire was used to implement an ad hoc survey of farmers as a source of primary information for the study. 
The dataset used stems from the 2012 survey entitled "Farmers and Social Capital" (IESA-CSIC, 2012). This individual survey was conducted by the Institute of Advanced Social Studies of the National Research Council (IESA-CSIC) with a representative sample of Andalusian 998 farmers. The sample was selected using a stratified, multistage design and probability sampling. In order to reduce sample dispersion and facilitate the fieldwork, first, municipalities were randomly selected in the different counties before randomly selecting farmers. The maximum expected absolute error term $(p=q=0.5)$ is $\pm 3.5 \%$ with a confidence level of $95 \%$.

The main purpose of the survey was to collect data regarding farmers' contribution to agricultural social capital, as already stated in Section 2.3 and Table A1 in Appendix. Table 1 summarizes the main descriptive statistics regarding the indicators considered in the analysis.

\section{TABLE 1 AROUND HERE}

It is also worth pointing out that the questionnaire also included questions related to farmers' demographic (gender, age and marital status), socioeconomic (income, involvement in activities other than agriculture and variables related to the level of education and specific professional agricultural training) and farm structure characteristics (farm size, type of tenancy, rain-fed or irrigated land, existence of a successor and the level of investment in fixed capital -machinery, groves, etc.). These variables were included to further analyze the factors that affect famers' contribution to agricultural social capital. The descriptive statistics of these variables are reported in Table 2.

TABLE 2 AROUND HERE

\section{Measuring farmers' contribution to agricultural social capital: a composite indicator approach}

This section describes the procedure employed to construct a composite indicator to measure farmers' contribution to agricultural social capital. For this purpose, we have followed the sequence suggested by the OECD-JRC (2008) based on the following 10 stages:

1. Development of the theoretical framework

2. Selection of base indicators

3. Imputation of missing data

4. Multivariate analysis

5. Data normalization

6. Assignment of weightings and aggregation

7. Robustness and sensitivity analyses

8. Analysis of the relationship of the calculated indices with other variables 
9. Analysis of the relationship between the indices calculated and the original data

10. Presentation and diffusion of results.

The first two stages (Development of theoretical framework and Selection of base indicators) have already been discussed in sections 2 and 3, respectively. No further comments are now required regarding stages 3 and 4 (Imputation of missing data and Multivariate analysis), since further details are given in section 5.1, where the main results of the Principal Components Analysis are reported.

Normalization (step 5) is a prerequisite for any aggregation of indicators because they are usually measured in different units. They therefore need to be expressed in homogeneous units in order to allow them to be compared and to perform arithmetical operations. After considering the existing normalization techniques (Freudenberg, 2003), we decided to employ "min-max" normalization in this study, so that the values of all the normalized indicators would vary within a dimensionless range $[0,1]$. After normalization, re-scaled indicator scores range between 0 (the worst value, that is, farmers' smallest contribution to agricultural social) and 1 (the largest contribution).

Once the values have been normalized, indicators need to be weighted and aggregated (step 6 ) in order to obtain the values of the composite indicator. Several valid procedures exist for this purpose (OECD-JRC, 2008). The lines below describe and justify the options taken for this stage.

The weighting stage enables us to distinguish the relative importance of the individual base indicators. The weighting techniques for constructing indices can be divided into "positive" or "endogenous" (weights are obtained via statistical procedures, without having to include value judgments) and "normative" or "exogenous" (weights are assigned on the basis of the opinion of experts and external decision-makers). Taking into account the complex and multidimensional nature of social capital and the limited capacity of the available experts to weight indicators of agricultural social capital on the basis of sound knowledge, "positive" techniques were considered the best option for this case. In reference to these techniques, it is worth mentioning those based on Principal Components Analysis (PCA), Data Envelopment Analysis (DEA) and regression analysis (see OECD-JRC, 2008 for a detailed analysis of the pros and cons of each alternative). The former is the most widely used in the literature because of its relative convenience and is also the chosen technique for this research.

Similarly, several options are available for aggregating base indicators into a single index. The selection process is not trivial, since it influences the type of compensation or "marginal rate of substitution" among indicators (Munda, 2008). Depending on the algebraic expression employed in the aggregation process, we may assume the possibility of total, partial or zero compensation among indicators. Briefly, additive linear functions implicitly assume total compensation among indicators and multiplicative and geometric functions permit partial compensation, while non-compensatory multicriteria functions prevent any type of compensation from taking place (Gómez-Limón and Sanchez-Fernandez, 2010). In this case, also considering the complex nature of social capital and the 
large number of base indicators required to include the different dimensions into the analysis, the additive linear method (total compensation among indicators) has been selected. ${ }^{1}$

Bearing in mind the decisions taken (PCA as the weighting technique and additive linear function as the aggregation procedure), the next step was to calculate the composite indicator for farmers' contribution to agricultural social capital (briefly, the Social Capital Index or SCI). Next, the quantitative procedure followed is fully explained.

PCA is a multivariate technique that reduces the number of explanatory variables, taking into account their intercorrelations. This technique aims to capture most of the observed variance of the explanatory variables using the smallest possible number of principal components. In this study, we apply PCA to the indicator dataset (52 indicators $\times 998$ farmers) in order to group the indicators that are most highly correlated and obtain the principal components $Z_{j}$. Following OECD-JRC (2008), only the principal components with eigenvalues higher than unity are retained. Furthermore, in order to facilitate the interpretation of these components, a Kaiser's varimax rotation is implemented.

Once the principal components have been extracted, we need to calculate the intermediate composite indicators $\left(I C I_{j}\right)$ corresponding to each of the principal components $j$. In order to do so, we consider a linear weighted aggregation of indicators as follows:

$$
I C I_{j i}=\sum_{k=1}^{k=n} w_{k j} I_{k i}
$$

where $\left.I C\right|_{j i}$ is the intermediate composite indicator for component $j$ and farmer $i, w_{k j}$ being the weighting of indicator $k$ in component $j$ and $l_{k i}$ the normalized indicator $k$ achieved by farmer $i$. The weightings $w_{k j}$ are derived from the factor loadings matrix obtained from PCA, following this expression:

$$
w_{k j}=\frac{\left(\text { factor_loading }_{k j}\right)^{2}}{\text { eigenvalue }_{j}}
$$

where factor_loading $k$ is the value of the factor loading of indicator $k$ in principal component $j$, and eigenvalue ${ }_{j}$ is the eigenvalue of the $j$ th principal component.

Finally, the Social Capital Index or SCl is calculated as the linear weighted aggregation of the intermediate composite indicators as follows:

$$
S C I_{i}=\sum_{j=1}^{j=n} \alpha_{j} I C I_{j i}
$$

where $S \mathrm{Sl}_{i}$ is the value of the composite indicator for the farmer $i$ and $\alpha_{j}$ is the weight applied to the intermediate sustainability indicator $j$ calculated as follows:

\footnotetext{
${ }^{1}$ In this sense it is worth pointing out that due to working with 52 base indicators, implementing any multiplicative or noncompensatory multicriteria functions (assumptions of partial or zero compensation, respectively) would result in values of zero for the composite indicators in almost all cases (farmers). The reason behind this outcome is the high probability that at least one of the base indicators considered would have a normalized value of zero. This is why these aggregation methods have no practical utility in cases like this, where the complexity of the concept measured requires taking into account a large number of base indicators.
} 


$$
\alpha_{j}=\frac{\text { eigenvalue }_{j}}{\sum_{j=1}^{j=n} \text { eigenvalue }_{j}}
$$

By definition, the values of the composite indicator obtained as explained above for individual farmers (i) range from 0 (farmers' smallest contribution to agricultural social) to 1 (the largest).

Finally, Stage 7 (Robustness and sensitivity analysis) aims to verify the reliability of the composite indicator obtained. Similarly, stages 8 and 9 (Analysis of the relationship between the index calculated and with other variables and with the original data) attempt to identify the base indicators that have the most influence on the composite indicator and to explain the relative importance of other variables for this index. Multivariate statistical techniques were employed in all of these stages, as described in the Results section.

\section{Results}

\subsection{PCA analysis: testing the dimensions of social capital}

After applying PCA to our indicator dataset (52 indicators $\times 998$ farmers), 14 principal components are retained, explaining $59.6 \%$ of the total variance. Furthermore, the KMO (KaiserMeyer-Olkin test) measure of sampling adequacy is 0.843 and Bartlett's test of sphericity is significant (chi-square=17285.1; $p$-value $<0.001$ ), allowing us to accept the entire PCA analysis implemented (Hair et al., 1998).

In order to understand the meaning of these components, the rotated factor loadings of the individual indicators can be analyzed, as Table 3 shows.

\section{TABLE 3 AROUND HERE}

The results in Table 3 suggest that the base indicators selected for each sub-dimension considered are adequate, as in most cases each sub-dimension is explained by one single principal component (that is, the indicators selected for each topic are highly correlated with the latent variable or sub-dimension analyzed) mainly scored by the indicators a priori chosen for measuring each particular sub-dimension (the indicators reach the highest loadings for factor $Z_{j}$ explaining the sub-dimension they were selected for). In this sense, we can see how component $Z_{1}$ explains the subdimension of civicness, $Z_{2}$ trust in public services, $Z_{3}$ corporate social capital, $Z_{7}$ community cohesiveness, $Z_{8}$ reciprocity, $Z_{9}$ trust in political institutions, $Z_{11}$ tolerance and social sanction and $Z_{13}$ safety.

However, the results of components $Z_{4}, Z_{5}$ and $Z_{6}$ are less evident. Component $Z_{4}$ explains the social capital derived from the closest family networks, information that was collected by bonding (BOND1 and BOND3) and family thick trust indicators (TCKT1 and TCKT2). Component $Z_{5}$ accounts for friend networks, mainly composed of bridging indicators. Component $Z_{6}$ describes generalized social trust, which also includes the neighbors thick trust indicator (TCKT3). 
Finally, it is worth mentioning that the linking sub-dimension is covered by three principal components $\left(Z_{10}, Z_{12}, Z_{14}\right)$, while $Z_{10}$ explains general linking relations (LINK1 to LINK4) and $Z_{12}$ and $Z_{14}$ account for environmental associations (LINK6) and women and young people associations (LINK5), respectively.

\subsection{Farmers' contribution to agricultural social capital}

The results of the PCA have been used as input to build the Social Capital Index (SCI) proposed in expressions [1] to [4]. Thus, an individual value for this index $\left(S C I_{i}\right)$ has been calculated for each of the 998 farmers included in the sample. A summary descriptive analysis of the distribution of $\mathrm{SCl}_{i}$ can be observed in Table 4 (second row) and Figure 2. Furthermore, by implementing the KolmogorovSmirnov test we can retain the null hypothesis that the distribution of $\mathrm{SCl}_{i}$ is normal with a mean of 0.554 and a standard deviation of 0.081 .

\section{TABLE 4 AND FIGURE 2 AROUND HERE}

Once the $\mathrm{SCl}_{i}$ has been obtained for each farmer, the next step is to analyze the relationship between this composite indicator and other relevant variables (steps 8 and 9 in the guidelines provided by the OECD-JRC, 2008). This was done by implementing a regression model, in which some demographic and socioeconomic characteristics of farmers are analyzed together with key features of the farms considered and regional variables in an attempt to provide some explanation for the variance in farmers' contribution to agricultural social capital. Our selection of independent variables for the model is based largely on earlier studies (Putnam, 1995; Brehm and Rahn, 1997; Alesina and La Ferrara, 2000; Glaeser et al., 2002 and Rupasingha et al., 2006 among others) and also responds to data availability.

The method chosen to analyze the relationship between farmers' contribution to agricultural social capital and their personal and productive characteristics was a double-censored Tobit regression. Tobit models are estimated using maximum likelihood, a general method for obtaining parameter estimates and making statistical inferences on the estimates. This choice is justified by the upper and lower-bounded feature of the index constructed $\left(S \mathrm{Cl}_{i}\right.$ ranging from 0 to 1$)$, with the aim of avoiding the problem of biased estimators associated with the use of ordinary least squares (OLS) regressions on data of this sort (Simar and Wilson, 2007).

We therefore performed a Tobit regression whereby the dependent variable is the $S C I_{i}$ and demographic variables of the farm owners (gender, age and marital status), their socioeconomic data (farmers' income, percentage of time employed in agricultural activities and variables related to the level of education and specific professional agricultural training), structural farm variables (physical dimensions, farming/livestock business type, percentage of the farm owned by the farm operator and percentage of rain-fed land, degree of security on business' succession once retired and level of investment in fixed capital) as independent variables, along with two variables to control for potential regional differences, as community diversity is also likely to have different effects on the accumulation of social capital by farmers. 
The first of these regional variables is the type of county according to its socio-demographic and geographic features. Based on those characteristics, four different types of counties are considered ${ }^{2}$ :

- Type I (Deep Rural): Mountainous areas with extensive marginal crops, weak economy, ageing population but heavily reliant on agriculture.

- Type II (Traditional Mediterranean Rural): Weak economy with traditional inland Mediterranean olive groves, cereal farms and vineyards but open to economic diversification.

- $\quad$ Type III (Light Rural): Densely populated rural areas near big cities or touristy sites with dynamic economies.

- $\quad$ Type IV (Simply Rural): Heterogeneous areas with diverse agricultural systems mostly with an intensive production focus and potential economic diversification.

The second regional variable used is related to the rural development strategy adopted by each county, distinguishing between those where both LEADER and PRODER Initiatives were implemented and those where only PRODER was applied ${ }^{3}$. This would imply a different path of developmental policies and probably different forms and processes of emerging social capital.

The descriptive statistics of the regressors used are provided in Table 2.

The results of the regressions can be found in Table $5 .{ }^{4}$ First of all, the overall results support the use of the tobit regression approach with a significant $L R \chi^{2}$ of 138.28 , leading us to conclude that at least one of the regression coefficients in the model is not equal to zero and a low sigma value (0.0719) is a good indication of an appropriate fit. Furthermore, in order to check that multicollinearity is not a source of unbiased estimations, OLS regressions were also performed in order to obtain the variance inflation factor (VIF). VIF values were below 3 in all cases, indicating that multicollinearity is not a problem for the estimates obtained.

\section{TABLE 5 AROUND HERE}

We observe a weakly significant positive relationship between male farmers and their contribution to agricultural social capital. Traditionally in agriculture, males have been more likely to run farms. As found in previous empirical studies (Alesina and La Ferrara, 2000; Asante et al., 2011), our interpretation of this result is that women often carry the weight of the farm business plus an

\footnotetext{
${ }^{2}$ This county classification was used for the intermediate evaluation of the LEADER + Initiative in Andalusia conducted by the Agriculture and Fisheries Management Agency of Andalusia and the Institute of Advanced Social Studies (IESA-CSIC, 2006).

${ }^{3}$ LEADER is an EU Initiative designed to help rural actors consider the long-term potential of their local region by encouraging the implementation of integrated, high-quality and original strategies for sustainable development with a strong focus on partnerships and networks to exchange experiences. Similarly, PRODER (Operative Program for the Economic Development and Diversification of Rural Areas) is a national program designed and applied in Spain and cofunded by the EU with Structural Funds that is intended to boost development in rural areas by diversifying economic activities so as to improve the level of income and wellbeing of rural dwellers.

${ }^{4}$ Sample size dropped from 998 to 739 individuals since only farmers that provided full responses to all the questions regarding the variables used in this analysis were considered.
} 
important share of household and family activities, leaving them with less time to contribute to building up agricultural social capital. ${ }^{5}$ The relationship between age and farming social capital is first increasing and then decreasing, peaking at the age of 60 . This inverted u-shape is well known in the social capital literature (Putnam, 2000; Glaeser et al., 2002). Thus, younger farmers are increasingly more alert to obtaining information from sources that consider different ways of improving their vocation than older farmers. On the contrary, beyond the age of 60 , farmers' past experiences could make them satisfied, thus discouraging them from nurturing the social aspect of their farming business.

Furthermore, marital status seems to weakly affect the production of farming social capital, in line with the common notion in sociological and political analyses based on partial correlations, which indicate that married people are generally more socially involved than other people (Putnam, 1995).

Farmers' income and level of education, ceteris paribus, are positively correlated with the production of social capital and highly significant, except for university education, where no significant results were found. This is not surprising if one imagines that the same people who invest in standard forms of human capital like education also invest in social capital (Verba and Nie, 1987). Nonetheless, our results provide further evidence that investment in social capital declines as the opportunity cost of time rises (Putnam, 2000). Thus, the absence of significant results for university graduates may be an indication, albeit weak, that investment in farming social capital is partly driven by the opportunity cost of time. It could be also considered that farmers with university education do not use farming as their main professional activity (they may be part-time farmers but work as medical doctors, lawyers, engineers, etc.) and many of them do not even live in villages, but in cities. Relationships and the frequency of contact with other farmers, the people living in the village and institutions could be different and, as a consequence, may result in a different level of production of social capital. In any case, acquiring a better understanding of this relationship should be a key goal for future research.

Also as expected, the variables regarding farmers' professionalism and specialization (percentage of time employed in agricultural activities and specialized training in agriculture) also display significant coefficients. In this sense, results show that full-time farmers and those who have received agricultural training are significantly more likely to contribute farming social capital than those who use agriculture as a secondary professional activity and/or have not taken any specialized training courses. The level of specialization and technical knowledge acquired should thus be analyzed as a form of human capital acquisition, allowing us to assume that as specialization and the level of technical knowledge rises, the more they invest in social capital as a means to becoming more profitable in their business (Phillips, 1994).

The variables referring to farm structure also provide some interesting results. First, no significant results have been found regarding the size of the farm. This result may indicate that what

\footnotetext{
${ }^{5}$ Alesina and La Ferrara (2000, p.19) further verified that in fact, women do not participate less in voting, an act of participation which does not require a significant amount of time.
} 
really matters is the 'economic' size of the farm (as shown with the significant value reported for 'farmers' income'), not its 'physical' size.

Second, we use the percentage of farm owned as an equivalent to business ownership and expected a significant positive relationship between this variable and the social capital index. However, our results fail to confirm earlier findings that suggested that reduced mobility due to ownership is a major source of social capital formation (Di Pasquale and Glaeser, 1999; Glaeser et al., 2002). In order to measure mobility, we include the likelihood that someone will take over the business once the current farmer retires as a variable indicating the degree of attachment to the farm business. This variable is significant and has the expected sign, indicating that the greater the involvement in the farm business, the more likely it will be that the farmer is more civically active and increase his/her farming social capital.

Third, the relationship between agricultural social capital and productive intensification has also been analyzed by considering the percentage of rain-fed (vs. irrigated) land and the level of investment in fixed capital as compared to their county's counterparts. The significance of the coefficients estimated for both variables suggests that the formation of farming social capital at farmer level increases as natural (water availability) and artificial (fixed capital) capital also increase.

Lastly, by controlling for spatial/regional characteristics, it is possible to provide an explanation for regional differences in the formation of farming social capital. Unlike artificial or human capital, for which an individual's investment decisions are affected only by his or her own characteristics, we argue that farming social capital investment is likely to be shaped by the social sphere surrounding farmers (Glaeser and Sacerdote, 2000). In order to control for community diversity in our analysis, a dummy variable was incorporated into the regression to test for differences between having the farm in a LEADER or PRODER area, along with regional dummies for up to four types of counties identified on a socio-economic basis. These regional variables are highly statistically significant, confirming that the county a farm is located in has the expected effect on the production of farming social capital. Results indicate that farmers in communities with profound rural features and heavier dependence on farming activities (in particular, type I-Deep Rural- and IV -Simply Rural) have, ceteris paribus, higher levels of civic engagement than their less rural counterparts. Similar results were found in Rupasingha et al. (2006) for rural vs. urban dwellers. Furthermore, results indicate that farmers in LEADER areas are less likely (albeit weak significance) to invest in farming social capital than their counterparts in PRODER areas. One explanation for this result might be that the priority for rural development in areas under the LEADER initiative was not to primarily focus on reinforcing agricultural activities, but rather to diversify economic activities. In these cases farmers have not been really involved in the LEADER initiative. On the contrary, in many of the PRODER territories where farming activities are very important, the rural development strategy has emphasized agriculture modernization as a relevant tool. In summary, it seems that a combination of rurality and the presence of a consolidated farming sector in the area is important in determining the level of agricultural social capital accumulated at farmer level. 


\section{Conclusions}

Social capital has become a major topic in the literature over the last two decades due to its importance in facilitating the development process. In this sense, there is widespread agreement regarding the relevance of social capital in the ability of rural communities to guarantee sustainable development.

Notwithstanding, the concept of social capital is complex and therefore difficult to measure. In the literature, social capital has been analyzed from different points of view and measured using various indicators. In this research, we have encompassed all the dimensions and sub-dimensions of social capital and elaborated a measurement model to cover them all, making it possible to build a composite indicator for social capital at individual level. This model has been applied to Andalusian farmers in order to assess their contribution to agricultural social capital and subsequently identify which socioeconomic and structural factors are determinants of the production of social capital at farm level. The idea is that the accumulation of social capital among farmers will have a (positive) impact on the agricultural development and sustainability of rural areas.

Our analysis shows that socioeconomic factors affect the formation of social capital among farmers. In this sense, farmers with a greater involvement in the agricultural sector (full-time farmers, farmers who have completed agricultural training courses...) are also more likely to contribute to farming social capital. As regards farmers' demographic features, male farmers show a weak but significant and positive relationship with the contribution to agricultural social capital and it is also worth pointing out that there is a significant relationship between social capital and age. That outcome may be of particular interest to policymakers when designing and implementing agricultural policies aimed at achieving more sustainable agriculture. For instance, these data could be taken into account when developing some of the measures foreseen in the ongoing reform of Common Agricultural Policy, above all those concerning young farmers and the generational takeover or those addressing the definition of "active farmer" (based mainly on how dependent a farmer is on farming). Designing and implementing such measures appropriately may boost the formation of social capital and, therefore, become an important ingredient toward enhancing agricultural and rural development.

This study further supports the claim that place of residence is a significant determinant of the accumulation of individual social capital. Results show that the areas where farming and rurality figure prominently, so too does social capital. Similar outcomes had already been obtained by Evans and Syrett (2010) in their study on the social economy and local economic development, which highlights that rural areas record a higher score in social capital indicators than urban areas do. The relationship between rural and urban communities is a relevant issue within the new proposals by the EU concerning territorial policy. Some studies point out that relationships between farmers and non-farmers at the rural-urban interface generate social capital with a positive influence on the attitudes and beliefs of urban dwellers toward local agriculture (Sharp and Smith, 2003). In this sense, the farming sector could learn from this relationship to design new developmental strategies that would be shared with the non-farmer population of rural areas. 
We believe this research significantly contributes to the scant empirical literature on the accumulation of social capital among farmers, since it aids in constructing a more comprehensive indicator of social capital that takes into account the multidimensional, dynamic and contextual features of the concept. This approach could be used to develop more effective agriculture and rural development policies.

\section{Acknowledgments}

This research was made possible by the support provided by the Spanish Ministry of Economy and Competitiveness and FEDER through the research projects AGRIGOBERSOS (AGL2010-17560-C02-01) and CAPSOC (CSO2011-27465). Special thanks are given to the members of the Applied Statistics Technical Unit of IESA-CSIC.

\section{References}

AEA (Analistas Económicos de Andalucía), 2012. Informe anual del sector agrario en Andalucía 2010. AEA, Málaga.

Adesina, A.A., Baidu-Forson, J., 1995. Farmers' perception and adoption of new agricultural technology: Evidence from analyses in Burkina Faso and Guinea, West Africa. Agricultural Economics 13, 1-9.

Alesina, A., La Ferrara, E., 2000. Participation in heterogeneous communities. Quarterly Journal of Economics 115, 847-904.

Asante, B.O., Afari-Sefa, V., Bruce Sarpong, D., 2011. Determinants of small scale farmers' decision to join farmer based organizations in Ghana. African Journal of Agricultural Research 6, 2273-2279.

Barney, J., Hansen, M.H., 1994. Trustworthiness as a source of competitive advantage. Strategic Management Journal 15, 175-190.

Belliveau, M.A., O'Reilly, C.A., Wade, J.B., 1996. Social capital at the top: Effects of social similarity and status on CEO compensation. Academy of Management Journal 39, 1568-1593.

Brehm, J., Rahn, W., 1997. Individual-level evidence for the causes and consequences of social capital. American Journal of Political Science 41, 999-1023.

CAP (Consejería de Agricultura y Pesca), 2012a. Anuario de Estadísticas Agrarias y Pesqueras 2010. CAP, Sevilla.

CAP (Consejería de Agricultura y Pesca), 2012b. The agricultural and fisheries sector in Andalucía. Accessed June 2012, available at http://www.juntadeandalucia.es/agriculturaypesca/.

Coleman, J.S., 1988. Social capital in the creation of human capital. American Journal of Sociology 94, 95-120.

Coleman, J.S., 1990. Foundations of social theory. Harvard University Press, Harvard.

Di Pasquale, D., Glaeser, E. 1999. Incentives and social capital: Are homeowners better citizens? Journal of Urban Economics 45, 354-384.

Durlauf, S.N., Fafchamps, M., 2006. Social capital, in P. Aghion, S.N. Durlauf, eds., Handbook of Economic Growth. Elsevier, Amsterdam.

EU-DG Agri (European Union-Directorate-General for Agriculture and Rural Development), 2011. Agriculture in the European Union. Statistical and economic information. EU-Directorate-General for Agriculture and Rural Development, Brussels.

Evans, P. 1996. Government action, social capital and development: Reviewing the evidence on synergy. World Development 24, 1119-1132. 
Evans, M., Syrett, S., 2010. Generating Social Capital? The Social Economy and Local Economic Development. European Urban and Regional Studies 14, 55-74.

Fafchamps, M., Minten, B., 1998. Returns to social capital among trader, MSSD Discussion Paper No. 23. International Food Policy Research Institute, Washington DC.

Freudenberg, M., 2003. Composite indicators of country performance: a critical assessment. OECD Science, Technology and Industry Working Papers, 2003/16. OECD, Paris.

Glaeser, E.L., Laibson, D.I., Scheinkman, J.A., Soutter, C.L., 2000. Measuring trust. Quarterly Journal of Economics 115, 811-846.

Glaeser, E.L., Laibson, D. I., Sacerdote, B. 2002. The economic approach to social capital. Economic Journal 112, F437-F458.

Glaeser, E. and Sacerdote, B., 2000. The Social Consequences of Housing. National Bureau of Economic Research Working Paper 8034, Cambridge, MA.

Gómez-Limón, J.A., Sanchez-Fernandez, G., 2010. Empirical evaluation of agricultural sustainability using composite indicators. Ecological Economics 69, 1062-1075.

Granovetter, M., 1995. The economic sociology of firms and entrepreneurs, in A. Portes, ed., The Economic Sociology of Immigration: Essays on Networks, Ethnicity and Entrepreneurship. Russell Sage Foundation, New York.

Grootaert, C., 1998. Social Capital, Household Welfare and Poverty in Indonesia, Local Level Institutions Study. World Bank, Washington DC.

Grootaert, C., van Bastelaer, T., 2002. Understanding and measuring social capital: A multidisciplinary tool for practitioners. World Bank, Washington DC.

Guiso, L., Sapienza, P., Zingales, L., 2004. The role of social capital in financial development. American Economic Review 94, 526-556.

Hair, J. F., Anderson, R. E., Tatham, R. L., Black, W. C., 1998. Multivariate data analysis. Prentice Hall, Upper Saddle River, NJ.

IESA-CSIC (Instituto de Estudios Sociales Avanzados-CSIC), 2006. Actualización de la Evaluación intermedia de la Iniciativa Comunitaria LEADER + en Andalucía. Informes y Monografías E-0601. IESA-CSIC, Córdoba.

IESA-CSIC (Instituto de Estudios Sociales Avanzados-CSIC), 2009. Agrobarómetro de Andalucía,2009. Informes y Monografías E-0932. IESA-CSIC, Córdoba.

IESA-CSIC (Instituto de Estudios Sociales Avanzados-CSIC), 2012. Agricultores y capital social. Informes y Monografías E-1114. IESA-CSIC, Córdoba.

Jordan, J.L.., Anil, B., Munasib, A. 2010. Community Development and Local Social Capital. Journal of Agricultural and Applied Economics 42, 143-159.

Just, F. (ed.), 1990. Co-operatives and farmers' union in Western Europe: Collaborations and tensions. Sydjysk University, Esbjerg, 183 p.

Knack, S., Keefer, P., 1997. Does social capital have an economic payoff? A cross-country investigation. Quarterly Journal of Economics 112, 1251-1288.

La Porta, R., Lopez-de-Silanes, F., Shleifer, A., Vishny, R.W., 1997. Trust in large organizations. American Economic Review 87, 333-338.

MARM (Ministerio de Medio Ambiente y Medio Rural y Marino), 2010. Anuario de Estadística 2009. MARM, Madrid.

Mathijs, E. 2003. Social capital and farmers' willingness to adopt countryside stewardship schemes. Outlook on Agriculture 32, 13-16.

Monge, M., Hartwich, F., Halgin, D. 2008. How Change Agents and Social Capital Influence the Adoption of Innovations among Small Farmers. Evidence from Social Networks in Rural Bolivia. Discussion Paper 00761. International Food and Policy Research Institute (IFPRI), Washington. 
Montgomery, J., 1991. Social networks and labor-market outcomes: Toward an economic analysis. American Economic Review 81, 1408-1418.

Moyano, E., 1995. Farmers' unions and restructuring of European agriculture. Sociologia Ruralis 35, 348-365.

Munasib, A.B.A., Jordan, J.L. 2011. The effect of social capital on the choice to use sustainable agricultural practices. Journal of Agricultural and Applied Economics 43, 213-227.

Munda, G., 2008. Social multi-criteria evaluation for a sustainable economy. Springer-Verlag, New York.

Nahapiet, J., Ghoshal, S. 1998. Social capital, intellectual capital, and the organizational advantage. Academy of Management Review 23, 242-266.

Narayan, D., 1999. Bonds and bridges social capital and poverty. Policy Research WP n. 2167. The World Bank, Washington DC.

Nardone, G., Sisto, R., Lopolito, A. 2010. Social capital in the LEADER initiative: a methodological approach. Journal of Rural Studies 26, 63-72

Nyhan Jones, V., Woolcock, M., 2007. Using mixed methods to assess social capital in low income countries: A practical guide. Brooks World Poverty Institute Working Paper Series 1207, BWPI. The University of Manchester, Manchester.

OECD (Organization for Economic Co-operation and Development) - JRC (Joint Research Centre), 2008. Handbook on constructing composite indicators. Methodology and user guide. OECD, Paris.

Onyx, J., Bullen, P., 2000. Measuring social capital in five communities. Journal of Applied Behavioral Science 36, 23-42.

Ostrom, E., 2000. Social capital: a fad or a fundamental concept? In P. Dasgupta and I. Serageldin, eds., Social capital. A multifaceted perspective. The World Bank, Washington DC.

Phillips, J.M., 1994. Farmer education and farmer efficiency: a meta-analysis. Economic Development and Cultural Change 43, 149-165.

Putnam, R.D., 1995. Bowling alone: America's declining social capital. Journal of Democracy 6, 65-78.

Putnam, R.D., 2000. Bowling alone. The collapse and revival of American community. Simon Schuster, New York.

Putnam, R.D., Leonardi, R., Nanetti, R.Y., 1993. Making democracy work: Civic traditions in modern Italy. Princeton University Press, Princeton.

Rauch, J., Casella, A., 2001. Overcoming Informational barriers to international resource allocation: Prices and group ties. Economic Journal 113, 21-42.

Rupasingha, A., Goetz, S.J., Freshwater, D., 2006. The production of social capital in US counties. The Journal of Socio-Economics 35, 83-101.

Sabatini, F., 2008. Social capital and the quality of economic development. Kyklos 61, 466-499.

Sabatini, F., 2009a. Social capital as social networks: a new framework for measurement and an empirical analysis of its determinants and consequences. The Journal of Socio-Economics 38, 429442.

Sabatini, F., 2009b. The relationship between trust and networks. An exploratory empirical analysis. Economic Bulletin 29, 661-672.

Sharp, J.S., Smith, M.B., 2003. Social capital and farming at the rural-urban interface: the importance of non-farmer and farmer relations. Agricultural Systems 76, 913-927.

Simar, L., Wilson, P., 2007. Estimation and inference in two-stage, semi-parametric models of production processes. Journal of Econometrics 136, 31-64.

Taylor, M., 1982. Community, anarchy and liberty. Cambridge University Press, Cambridge.

Trigilia, C., 2001. Social capital and local development. European Journal of Social Theory 4, 427-442. 
Uphoff, N., 1999, Understanding social capital: Learning from the analysis and experiences of participation. In P. Dasgupta and I. Serageldin, eds., Social capital. A multifaceted perspective. The World Bank, Washington DC.

Uphoff, N., Wijayaratna C.M., 2000. Demonstrated benefits from social capital: The productivity of farmer organizations in Gal Oya, Sri Lanka. World Development 28, 1875-1890.

Verba, S., Nie N.H., 1987. Participation in America. Political Democracy and Social Equality. The University of Chicago Press, Chicago.

WCED (United Nations World Commission on Environment and Development), 1987. Our Common Future. Oxford University Press, Oxford.

Woodhouse, A., 2006. Social capital and economic development in regional Australia: a case study. Journal of Rural Studies 20, 83-94.

Yli-Renko, H., Autio, E., Sapienza, H.J., 2001. Social capital, knowledge acquisition, and knowledge exploitation in young technology-based firms. Strategic Management Journal 22, 587-613. 
Table 1

Descriptive statistics of base indicators considered for the different sub-dimensions of social capital

\begin{tabular}{|c|c|c|c|c|c|c|}
\hline Dimension & Sub-dimension & $\begin{array}{l}\text { Variable } \\
\text { Label }^{\mathrm{a}}\end{array}$ & Min. & Max. & Mean & Std. Dev. \\
\hline \multirow{17}{*}{ 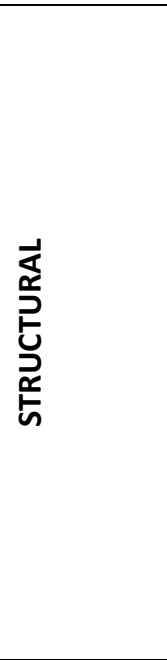 } & \multirow{3}{*}{ Bonding } & BOND1 & 1.0000 & 5.0000 & 4.4619 & 0.7039 \\
\hline & & BOND2 & 1.0000 & 5.0000 & 3.6052 & 1.1561 \\
\hline & & BOND3 & 1.0000 & 5.0000 & 4.5110 & 0.5571 \\
\hline & \multirow{3}{*}{ Bridging } & BRIDG1 & 1.0000 & 5.0000 & 4.1072 & 0.7571 \\
\hline & & BRIDG2 & 1.0000 & 5.0000 & 3.4439 & 1.1508 \\
\hline & & BRIDG3 & 2.0000 & 5.0000 & 4.1754 & 0.5433 \\
\hline & \multirow{6}{*}{ Linking } & LINK1 & 1.0000 & 3.0000 & 1.0802 & 0.3096 \\
\hline & & LINK2 & 1.0000 & 3.0000 & 1.1052 & 0.3351 \\
\hline & & LINK3 & 1.0000 & 3.0000 & 1.2495 & 0.5232 \\
\hline & & LINK4 & 1.0000 & 3.0000 & 1.1263 & 0.3499 \\
\hline & & LINK5 & 1.0000 & 3.0000 & 1.0531 & 0.2374 \\
\hline & & LINK6 & 1.0000 & 3.0000 & 1.0180 & 0.1605 \\
\hline & \multirow{5}{*}{ Corporate } & SCS1 & 1.0000 & 5.0000 & 2.4679 & 1.3770 \\
\hline & & SCS2 & 1.0000 & 5.0000 & 1.4559 & 0.9993 \\
\hline & & SCS3 & 1.0000 & 5.0000 & 1.5872 & 1.1339 \\
\hline & & SCS4 & 1.0000 & 5.0000 & 1.1232 & 0.5611 \\
\hline & & SCS5 & 0.0000 & 4.0000 & 1.4639 & 0.8891 \\
\hline \multirow{21}{*}{ 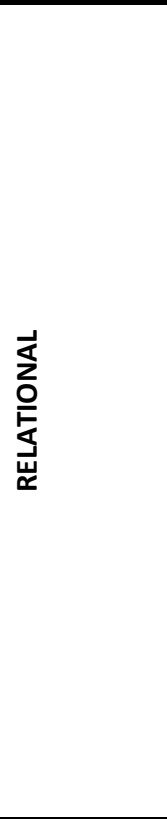 } & \multirow{3}{*}{$\begin{array}{l}\text { Knowledge- } \\
\text { Based Trust }\end{array}$} & TCKT1 & 1.0000 & 5.0000 & 4.6814 & 0.5152 \\
\hline & & TCKT2 & 1.0000 & 5.0000 & 4.4118 & 0.6252 \\
\hline & & TCKT3 & 1.0000 & 5.0000 & 3.9068 & 0.8212 \\
\hline & \multirow{3}{*}{$\begin{array}{l}\text { Trust Political } \\
\text { Institutions }\end{array}$} & TNTPI1 & 1.0000 & 5.0000 & 3.1002 & 1.0842 \\
\hline & & TNTPI2 & 1.0000 & 5.0000 & 3.1012 & 1.0217 \\
\hline & & TNTPI3 & 1.0000 & 5.0000 & 2.0010 & 0.9063 \\
\hline & \multirow{7}{*}{$\begin{array}{l}\text { Trust Public } \\
\text { Services }\end{array}$} & TNTPS1 & 1.0000 & 5.0000 & 3.9760 & 0.8542 \\
\hline & & TNTPS2 & 1.0000 & 5.0000 & 4.0681 & 0.7662 \\
\hline & & TNTPS3 & 1.0000 & 5.0000 & 3.8637 & 0.7689 \\
\hline & & TNTPS4 & 1.0000 & 5.0000 & 3.8267 & 0.8253 \\
\hline & & TNTPS5 & 1.0000 & 5.0000 & 3.0441 & 1.1384 \\
\hline & & TNTPS6 & 1.0000 & 5.0000 & 3.7094 & 0.8085 \\
\hline & & TNTPS7 & 1.0000 & 5.0000 & 3.4022 & 0.9577 \\
\hline & Generalized & TNTGS1 & 1.0000 & 5.0000 & 3.4870 & 0.8635 \\
\hline & Social Trust & TNTGS2 & 1.0000 & 5.0000 & 3.6703 & 0.7350 \\
\hline & Safety & SAFETY & 1.0000 & 5.0000 & 3.7916 & 0.8066 \\
\hline & \multirow{2}{*}{$\begin{array}{l}\text { Tolerance and } \\
\text { Social Sanction }\end{array}$} & TOLSS1 & 1.0000 & 5.0000 & 3.8958 & 0.8795 \\
\hline & & TOLSS2 & 1.0000 & 5.0000 & 4.0361 & 0.7762 \\
\hline & \multirow{3}{*}{$\begin{array}{l}\text { Generalized } \\
\text { Reciprocity }\end{array}$} & GENRC1 & 1.0000 & 5.0000 & 3.6854 & 0.8032 \\
\hline & & GENRC2 & 1.0000 & 5.0000 & 3.6764 & 0.9160 \\
\hline & & GENRC3 & 1.0000 & 5.0000 & 2.8848 & 0.9657 \\
\hline \multirow{14}{*}{ 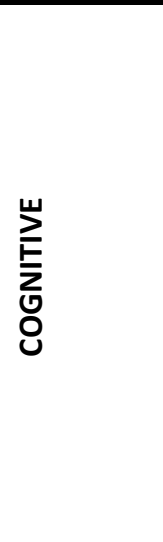 } & \multirow{4}{*}{$\begin{array}{l}\text { Community } \\
\text { Cohesiveness }\end{array}$} & COMC1 & 1.0000 & 5.0000 & 2.3476 & 1.0894 \\
\hline & & COMC2 & 1.0000 & 5.0000 & 2.2566 & 1.0167 \\
\hline & & соMC3 & 1.0000 & 5.0000 & 1.5476 & 0.6698 \\
\hline & & COMC4 & 1.0000 & 5.0000 & 1.6971 & 0.7793 \\
\hline & \multirow{10}{*}{ Civicness } & CIVIC1 & 1.0000 & 5.0000 & 3.9319 & 0.9992 \\
\hline & & CIVIC2 & 1.0000 & 5.0000 & 3.6313 & 0.9855 \\
\hline & & CIVIC3 & 1.0000 & 5.0000 & 3.3627 & 1.0236 \\
\hline & & CIVIC4 & 1.0000 & 5.0000 & 3.5671 & 0.9538 \\
\hline & & CIVIC5 & 1.0000 & 5.0000 & 2.9980 & 1.1269 \\
\hline & & CIVIC6 & 1.0000 & 5.0000 & 3.4349 & 1.0081 \\
\hline & & CIVIC7 & 1.0000 & 5.0000 & 3.1894 & 1.0180 \\
\hline & & CIVIC8 & 1.0000 & 5.0000 & 2.9349 & 0.9621 \\
\hline & & CIVIC9 & 1.0000 & 5.0000 & 3.0859 & 0.9842 \\
\hline & & CIVIC10 & 1.0000 & 5.0000 & 2.6393 & 1.0745 \\
\hline
\end{tabular}

${ }^{a}$ Full details of observable variables used in the analysis are reported in the Appendix (Table A1). 
Table 2

Descriptive statistics of the sample $(n=998)$

\begin{tabular}{|c|c|c|}
\hline Variables & Category & $\%$ \\
\hline \multicolumn{3}{|l|}{ Demographic } \\
\hline \multirow{2}{*}{ Gender } & Male & 69.6 \\
\hline & Female & 30.4 \\
\hline \multirow{3}{*}{ Age } & $<40$ & 11.8 \\
\hline & $41-65$ & 55.3 \\
\hline & $>65$ & 32.9 \\
\hline \multirow{2}{*}{ Marital status } & Married or living with partner & 83.3 \\
\hline & Living alone & 16.7 \\
\hline \multicolumn{3}{|l|}{ Socio-economic } \\
\hline \multirow{5}{*}{ Income (scale 1-10) } & $1-2(>€ 9,000 /$ year $)$ & 33.4 \\
\hline & 3-4 (€9,000/year - €14,999/year) & 39.6 \\
\hline & 5-6 (€15,000/year - €20,999/year) & 17.3 \\
\hline & 7-8 (€21,000/year - €26,999/year) & 5.8 \\
\hline & $9-10(<=€ 27,000 /$ year $)$ & 3.8 \\
\hline \multirow{5}{*}{$\begin{array}{l}\% \text { of time employed in } \\
\text { agricultural activities }\end{array}$} & $0 \%^{a}$ & 15.5 \\
\hline & $<=25 \%$ & 35.9 \\
\hline & $26 \%-50 \%$ & 12.4 \\
\hline & $51 \%-75 \%$ & 4.7 \\
\hline & $>75 \%$ & 31.5 \\
\hline \multirow{4}{*}{ Education } & No studies & 41.8 \\
\hline & Primary education & 33.9 \\
\hline & Secondary education & 14.9 \\
\hline & University degree & 9.4 \\
\hline \multirow{2}{*}{$\begin{array}{l}\text { Have you completed a specific } \\
\text { training course in agriculture? }\end{array}$} & Yes & 40.5 \\
\hline & No & 59.5 \\
\hline \multicolumn{3}{|l|}{ Farm structure } \\
\hline \multirow{7}{*}{ Farm size } & 0 ha (only livestock) & 0.4 \\
\hline & $<1$ ha & 19.7 \\
\hline & $1-5$ ha & 36.3 \\
\hline & $6-20$ ha & 24.6 \\
\hline & $21-50$ ha & 8.9 \\
\hline & $>50$ ha & 5.0 \\
\hline & No response & 5.1 \\
\hline \multirow{3}{*}{ Farm tenancy } & Owned & 85.2 \\
\hline & Rented & 7.2 \\
\hline & Owned \& Rented & 7.6 \\
\hline \multirow{3}{*}{ Type of land } & Irrigated & 22.1 \\
\hline & Rain-fed & 57.6 \\
\hline & Irrigated \& rain-fed & 20.3 \\
\hline \multirow{6}{*}{$\begin{array}{l}\text { Is there anyone to continue the } \\
\text { business once you retire? }\end{array}$} & Yes for sure & 24.3 \\
\hline & Quite likely & 22.3 \\
\hline & Maybe yes, maybe no & 10.9 \\
\hline & Very unlikely & 16.3 \\
\hline & Not for sure & 11.5 \\
\hline & Don't know & 14.7 \\
\hline \multirow{5}{*}{$\begin{array}{l}\text { Relative level of investment in } \\
\text { fixed capital (scale 1-5) }\end{array}$} & 1 (much lower than the average in the county) & 17.1 \\
\hline & 2 (lower than the average in the county) & 28.2 \\
\hline & 3 (similar than the average in the county) & 42.0 \\
\hline & 4 (higher than the average in the county) & 8.9 \\
\hline & 5 (much higher than the average in the county) & 3.8 \\
\hline \multicolumn{3}{|l|}{ Regional feature of farms } \\
\hline \multirow{4}{*}{ County type } & I. Deep Rural & 38.5 \\
\hline & II. Traditional Mediterranean Rural & 15.6 \\
\hline & III. Light Rural & 34.2 \\
\hline & IV. Simply Rural & 11.7 \\
\hline \multirow{2}{*}{ Rural development type } & Leader & 59.2 \\
\hline & PRODER & 40.8 \\
\hline
\end{tabular}

${ }^{\mathrm{a}}$ Farm owners but not directly involved in farming activities. 
Table 3

Rotated-components matrix from PCA (factor loadings) ${ }^{a}$

\begin{tabular}{|c|c|c|c|c|c|c|c|c|c|c|c|c|c|c|c|c|}
\hline \multirow{2}{*}{\multicolumn{2}{|c|}{ Indicators $^{b}$}} & \multicolumn{14}{|c|}{ Components } & \multirow{2}{*}{$\begin{array}{l}\text { Commu- } \\
\text { nalities }\end{array}$} \\
\hline & & $\mathrm{Z}_{1}$ & $\mathrm{z}_{2}$ & $\mathrm{Z}_{3}$ & $\mathrm{Z}_{4}$ & $Z_{5}$ & $Z_{6}$ & $\mathrm{z}_{7}$ & $Z_{8}$ & $Z_{9}$ & $Z_{10}$ & $Z_{11}$ & $Z_{12}$ & $Z_{13}$ & $Z_{14}$ & \\
\hline \multirow{17}{*}{ 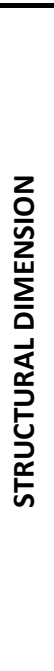 } & BOND1 & .089 & .047 & .019 & .630 & .358 & .003 & -.041 & -.082 & .053 & .105 & .042 & -.038 & .164 & .079 & .594 \\
\hline & BOND2 & .150 & .022 & .183 & .142 & .698 & -.048 & -.073 & .039 & -.059 & .061 & -.032 & .001 & .160 & .088 & .615 \\
\hline & BOND3 & .153 & -.015 & -.047 & .737 & .210 & -.061 & -.009 & -.091 & .084 & .096 & .015 & -.007 & .077 & .034 & .649 \\
\hline & BRIDG1 & .148 & .016 & .014 & .355 & .536 & .169 & -.004 & .147 & .016 & .013 & -.013 & .037 & -.297 & -.021 & .576 \\
\hline & BRIDG2 & .185 & .015 & .222 & .038 & .739 & .115 & .012 & .067 & -.029 & .029 & -.028 & -.010 & .010 & -.067 & .656 \\
\hline & BRIDG3 & .066 & .006 & -.005 & .445 & .483 & .195 & .111 & .038 & .062 & .053 & .060 & .029 & -.183 & .010 & .532 \\
\hline & LINK1 & .134 & -.071 & .024 & -.028 & -.057 & .100 & -.017 & .134 & -.006 & .507 & -.001 & .349 & .004 & -.005 & .434 \\
\hline & LINK2 & .038 & .040 & -.026 & -.003 & .141 & -.063 & -.066 & .002 & -.050 & .602 & .021 & .101 & .015 & .001 & .408 \\
\hline & LINK3 & -.006 & .005 & .177 & .138 & -.017 & .035 & -.084 & .032 & -.024 & .613 & .012 & -.181 & -.068 & .152 & .497 \\
\hline & LINK4 & .121 & .023 & .094 & .009 & -.003 & .027 & -.002 & .000 & -.024 & .702 & -.055 & .032 & -.039 & -.119 & .538 \\
\hline & LINK5 & .057 & -.049 & .025 & .033 & .010 & .034 & -.044 & -.006 & .002 & -.010 & -.049 & -.009 & .031 & .917 & .854 \\
\hline & LINK6 & .072 & .003 & -.040 & .037 & .033 & -.044 & -.045 & -.047 & -.064 & .127 & .019 & .805 & .103 & -.016 & .695 \\
\hline & CSC1 & .104 & .168 & .602 & .032 & .214 & .051 & -.091 & .105 & -.120 & .108 & -.079 & -.085 & .110 & .068 & .527 \\
\hline & $\mathrm{CSC} 2$ & .103 & -.024 & .673 & .011 & .065 & -.021 & -.045 & .113 & -.007 & .137 & .054 & -.057 & -.005 & .061 & .513 \\
\hline & $\mathrm{CSC} 3$ & .083 & -.002 & .660 & .012 & .123 & .067 & .051 & -190 & .101 & -.084 & .070 & .104 & .105 & -.135 & .563 \\
\hline & $\mathrm{CSC} 4$ & .143 & .089 & .545 & -.020 & -.021 & -.028 & .008 & -.020 & -.006 & .094 & -.085 & -.020 & -.310 & .023 & .440 \\
\hline & $\mathrm{CSC} 5$ & .122 & -.056 & .783 & .058 & .056 & .022 & .017 & -.071 & -.002 & .026 & .008 & .017 & -.006 & .013 & .644 \\
\hline \multirow{21}{*}{ 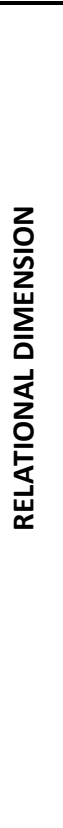 } & & .119 & .152 & .092 & .769 & -.046 & .143 & -.040 & .071 & -.072 & -.043 & .010 & .044 & -.083 & -.039 & .684 \\
\hline & TCKT2 & .143 & .227 & .093 & .521 & -.075 & .465 & -.116 & .224 & -.145 & -.085 & -.023 & .093 & -.144 & -.026 & .696 \\
\hline & TCКT3 & .103 & .250 & .033 & .208 & .064 & .775 & .037 & 179 & .019 & -.049 & .022 & -.033 & -.039 & -.020 & .762 \\
\hline & & .051 & .280 & .024 & .053 & -.073 & 109 & .038 & .096 & .666 & -.115 & -.001 & .038 & .064 & .058 & .578 \\
\hline & TNTPI2 & .078 & .353 & -.070 & .018 & -.022 & .014 & -.045 & .165 & .610 & -.096 & -.035 & .005 & -.147 & .033 & .572 \\
\hline & TNTPI3 & .079 & .107 & -.006 & -.023 & .008 & .170 & -.007 & .112 & .697 & .039 & .006 & -.096 & .077 & -.072 & .568 \\
\hline & TNTPS1 & .099 & .502 & .091 & .185 & -.055 & .055 & .107 & .135 & .191 & -.075 & .090 & .262 & -.140 & .09 & .487 \\
\hline & TNTPS2 & .107 & .648 & .070 & .224 & -.018 & .064 & .045 & .061 & .122 & .016 & .016 & .163 & .005 & -.001 & .538 \\
\hline & TNTPS3 & .093 & .698 & .044 & .142 & -.026 & .062 & .028 & .084 & .018 & .142 & .097 & -.035 & -.038 & $-.1<$ & .583 \\
\hline & TNTPS4 & .002 & .685 & .004 & .072 & .008 & .054 & -.006 & .104 & .176 & -.076 & .025 & .077 & -.015 & .021 & .533 \\
\hline & TNTPS5 & -.039 & .577 & -.006 & -.126 & .093 & .104 & .123 & .213 & .218 & -.033 & -.094 & .059 & -.065 & .04 & .497 \\
\hline & TNTPS6 & .087 & .728 & -.019 & -.079 & .096 & .072 & .011 & -.030 & .008 & .071 & .049 & -.154 & .22 & .0 & .640 \\
\hline & TNTPS7 & .050 & .714 & .010 & -.078 & .014 & .171 & .016 & -.016 & .025 & -.012 & .018 & -.24 & .140 & -.04 & .631 \\
\hline & TNTGS1 & .089 & .094 & .067 & -.013 & .056 & .622 & -.024 & .120 & .253 & .106 & .076 & .130 & .210 & .132 & .586 \\
\hline & & .119 & .146 & -.024 & .020 & .129 & .759 & .122 & .058 & .154 & .037 & -.023 & -.112 & .039 & & .689 \\
\hline & & .046 & .189 & -.013 & .004 & .021 & .192 & .191 & .141 & .082 & -.138 & -.123 & .179 & .544 & .078 & .507 \\
\hline & TOLSS1 & .076 & .085 & -.003 & .021 & -.066 & -.031 & -.025 & .070 & .015 & .029 & .828 & -.042 & .022 & .113 & .726 \\
\hline & & .089 & .057 & .004 & .031 & .036 & .074 & -.068 & .029 & -.034 & -.058 & .788 & .068 & -.084 & -.17 & .693 \\
\hline & & .033 & .202 & -.018 & -.047 & .062 & .148 & .001 & .642 & .101 & -.017 & .117 & -.040 & .157 & .014 & .533 \\
\hline & GENRC2 & .151 & .191 & .103 & .074 & .037 & .096 & .139 & .627 & .068 & .097 & .076 & .076 & -.079 & .037 & .531 \\
\hline & GENRC3 & .079 & .032 & -.130 & -.010 & .119 & .116 & .159 & .655 & .226 & .063 & -.066 & -.049 & .044 & -.057 & .573 \\
\hline \multirow{14}{*}{ 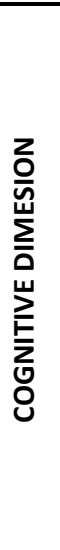 } & COMC1 & -.009 & .087 & .044 & -.082 & .100 & .058 & .720 & -.087 & .077 & -.110 & .002 & .059 & -.012 & -.006 & .577 \\
\hline & COMC2 & -.049 & .133 & -.091 & -.120 & .055 & .051 & .687 & .056 & .031 & -.092 & -.106 & .054 & -.107 & -.058 & .563 \\
\hline & сомс3 & -.133 & -.079 & -.050 & .111 & -.113 & -.083 & .670 & .193 & -.080 & -.060 & .035 & -.174 & .080 & .079 & .598 \\
\hline & COMC4 & -.015 & .042 & .037 & .061 & -.172 & .078 & .598 & .205 & -.065 & .127 & -.036 & -.042 & .275 & -.075 & .548 \\
\hline & CIVIC1 & .333 & .112 & .331 & .104 & .343 & -.049 & -.087 & .242 & -.155 & -.018 & .004 & .043 & .317 & -.119 & .571 \\
\hline & CIVIC2 & .582 & .005 & .133 & .303 & .136 & .026 & -.046 & .179 & .081 & .003 & -.031 & .032 & .182 & -.070 & .548 \\
\hline & CIVIC3 & .740 & -.039 & .044 & .117 & .042 & -.035 & -.023 & .056 & .207 & -.021 & .081 & .027 & .060 & -.043 & .627 \\
\hline & CIVIC4 & .757 & -.039 & .085 & .204 & .024 & -.015 & -.036 & -.003 & .160 & .078 & .148 & -.031 & .105 & -.104 & .702 \\
\hline & CIVIC5 & .794 & .040 & .080 & .096 & .025 & .038 & -.042 & -.043 & .019 & .159 & .024 & -.027 & .059 & -.020 & .684 \\
\hline & CIVIC6 & .459 & .225 & .306 & -.045 & .293 & .097 & -.064 & .148 & -.251 & -.035 & -.027 & .067 & .125 & .000 & .563 \\
\hline & CIVIC7 & .636 & .100 & .080 & .094 & .170 & .145 & -.013 & .163 & -.049 & -.031 & -.086 & .139 & .021 & .045 & .539 \\
\hline & CIVIC8 & .818 & .099 & .084 & -.078 & .096 & .063 & -.020 & .079 & .068 & -.013 & .033 & .010 & -.106 & .105 & .740 \\
\hline & CIVIC9 & .806 & .068 & .077 & .009 & .058 & .073 & -.007 & -.010 & -.042 & .062 & .060 & .050 & -.128 & .082 & .704 \\
\hline & CIVIC10 & .803 & .111 & .072 & -.022 & .031 & .098 & -.022 & -.042 & -.082 & .120 & -.005 & -.015 & -.100 & .045 & .709 \\
\hline
\end{tabular}


Table 4

Distribution of $\mathrm{SCl}_{i}$. Summary statistics

\begin{tabular}{|c|c|c|c|c|c|c|}
\hline & n & Min. & Max. & Mean & Std. Dev. & $\begin{array}{l}\text { Kolmogorov- } \\
\text { Smirnov }^{\mathrm{a}}\end{array}$ \\
\hline$S C I_{i}$ (farmers) & 998 & .280 & .855 & .554 & .0809 & $.750 \quad(.628)$ \\
\hline
\end{tabular}

${ }^{a}$ Statistic testing the null hypothesis that the sample is drawn from a normal distributed population (p-value in brackets). 
Table 5

Results of the double-censored Tobit regression to analyze the determinants of farmers' contribution to agricultural social capital

\begin{tabular}{|c|c|}
\hline Variables & ISC $_{\mathbf{i}}$ \\
\hline Constant & $.4090 * * *$ \\
\hline \multicolumn{2}{|l|}{ Demographic } \\
\hline Gender (male $=1$ ) & $.0115^{*}$ \\
\hline Age (year) & $.0036 * *$ \\
\hline $\operatorname{Age}^{2}\left(\right.$ year $\left.^{2}\right)$ & $-.00003 * *$ \\
\hline Married or living with couple (yes $=1$ ) & $.0140^{*}$ \\
\hline \multicolumn{2}{|l|}{ Socio-economic } \\
\hline Farmers' income (scale 1-10) & $.0037 * * *$ \\
\hline$\%$ of time employed in agricultural activities & $.0001^{* *}$ \\
\hline Primary Education $^{a}$ & $.0122 *$ \\
\hline Secondary Education ${ }^{a}$ & $.0185^{*}$ \\
\hline University Education $^{a}$ & .0090 \\
\hline Agric. training received (yes $=1$ ) & $.0178 * * *$ \\
\hline \multicolumn{2}{|l|}{ Farm structure } \\
\hline Farm size (ha) & -.00003 \\
\hline$\%$ area owned & -.00012 \\
\hline$\%$ of rain-fed land & $-.00012^{*}$ \\
\hline $\begin{array}{l}\text { Is there anyone to continue the business once you retire? } \\
\text { ( } 5=\text { = es for sure; } 4=\text { very likely } 3=\text { maybe yes/maybe not; } 2= \\
\text { very unlikely; } 1=\text { No) }\end{array}$ & $.0093 * * *$ \\
\hline Degree of investment in fixed capital (scale 1-5) & $.0064^{*}$ \\
\hline \multicolumn{2}{|l|}{ Regional } \\
\hline County type I (Deep Rural) ${ }^{\mathrm{a}}$ & $.03008 * * *$ \\
\hline County type II (Traditional Mediterranean Rural) ${ }^{\mathrm{a}}$ & .00645 \\
\hline County type IV (Simply Rural) $^{\text {a }}$ & $.0382 * * *$ \\
\hline Rural development Leader type (yes $=1$ ) & $-.00996 *$ \\
\hline$N$ & 739 \\
\hline Log likelihood & 896.68 \\
\hline $\operatorname{LR} \chi^{2}$ & $138.28 * * *$ \\
\hline Pseudos- $R^{2}$ & -0.0843 \\
\hline Sigma & .0719 \\
\hline
\end{tabular}

Significance level: ${ }^{* * *} p<0.01 ;{ }^{* *} p<0.05 ;{ }^{*} p<0.1$.

${ }^{a}$ Omitted categories: No education (school certificate), County type III (Light Rural). 


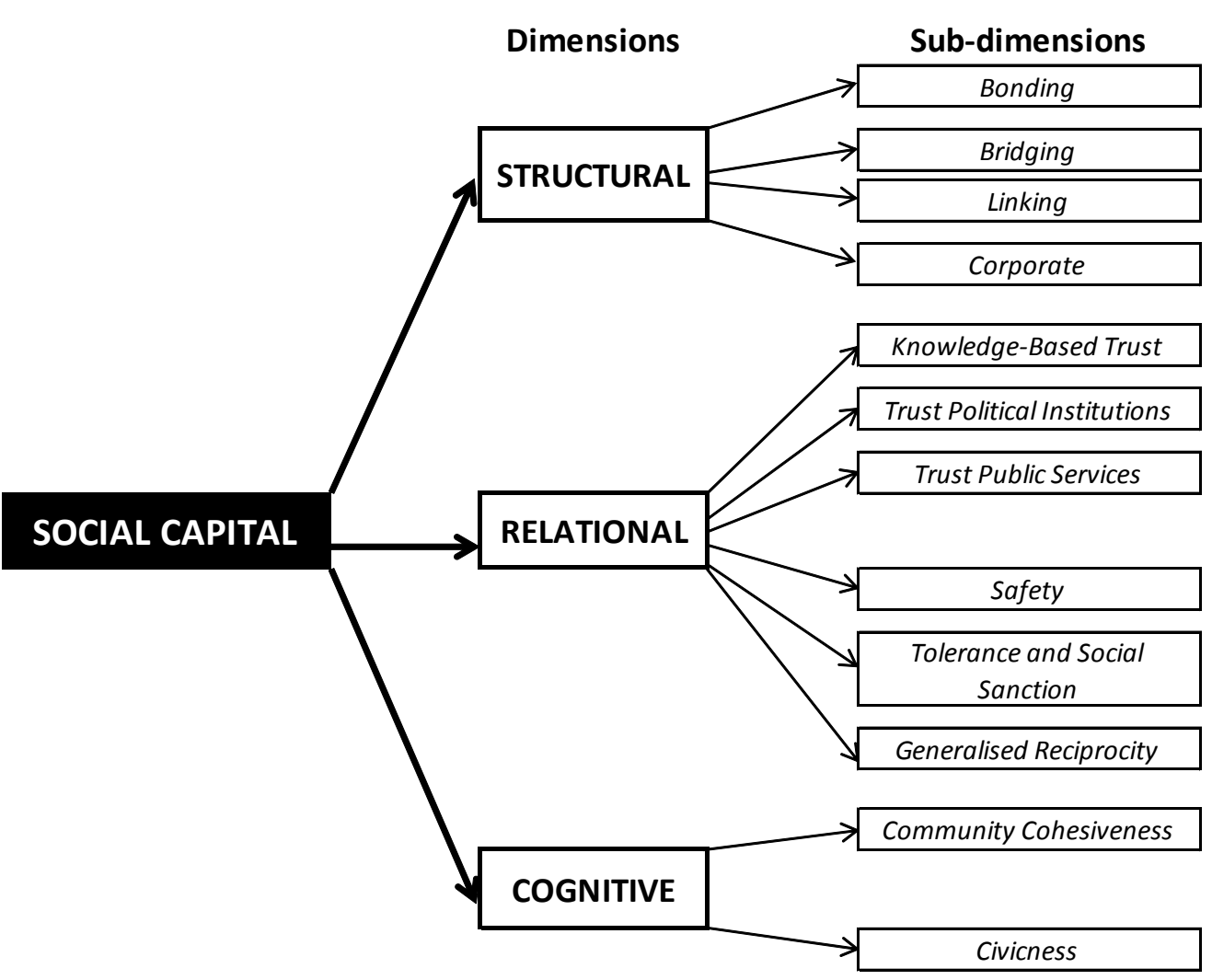

Fig. 1. Dimensions and sub-dimensions of social capital 


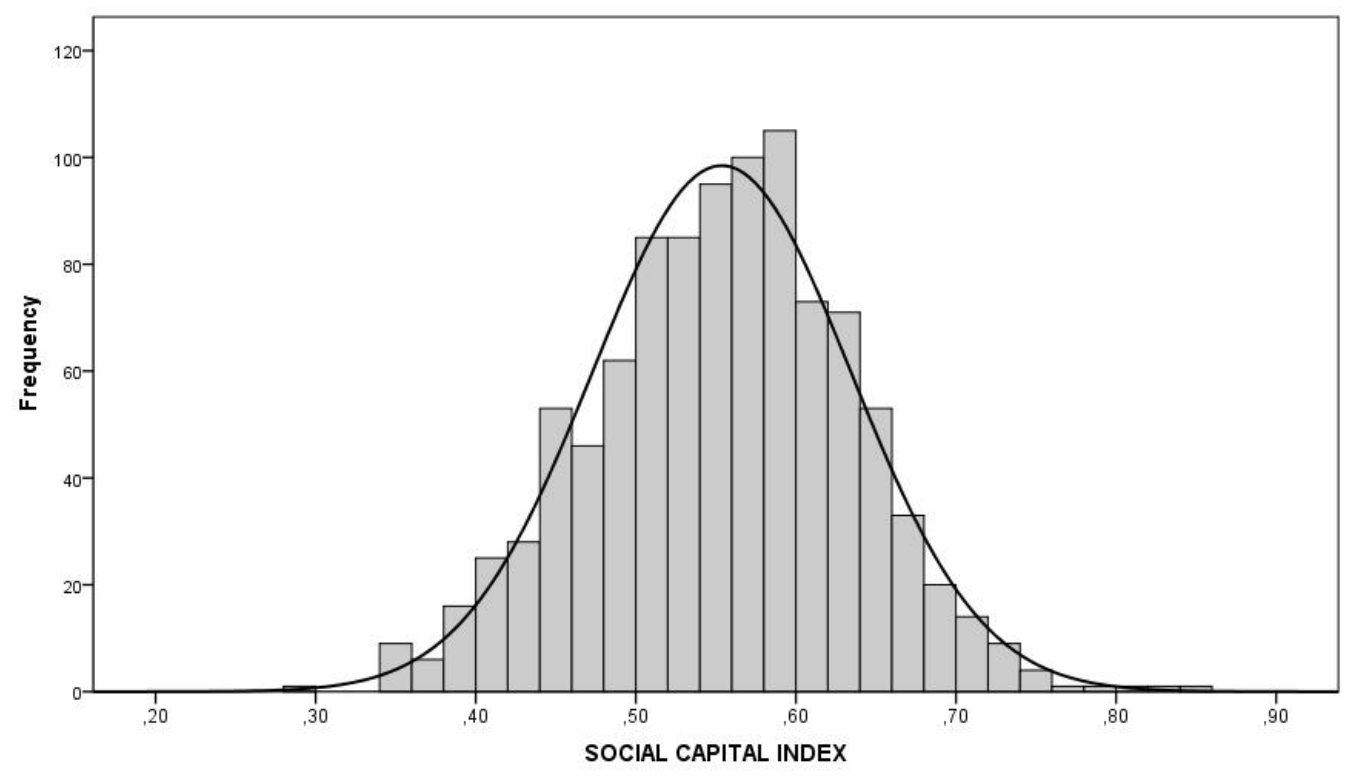

Fig. 2. Distribution of $S C I_{i}$ 
APPENDIX

Table A1

List of indicators used to measure farmers' contribution to agricultural social capital

\begin{tabular}{|c|c|c|c|c|}
\hline $\begin{array}{l}\text { Dimen } \\
\text {-sion }\end{array}$ & $\begin{array}{l}\text { Sub-di- } \\
\text { mension }\end{array}$ & $\begin{array}{l}\text { Variable } \\
\text { Label }\end{array}$ & Description & Possible responses \\
\hline \multirow{17}{*}{ 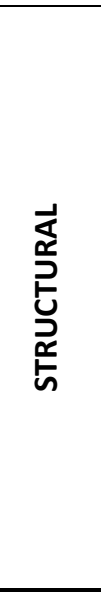 } & \multirow{3}{*}{ Bonding } & BOND1 & In the last 12 months, how often have you met with your close family? & 1 to 5 where 5 represents the highest level \\
\hline & & BOND2 & How often do you talk to your close family about agricultural issues? & 1 to 5 where 5 represents the highest level \\
\hline & & BOND3 & How satisfied are you with the relationship you have with your close family? & 1 to 5 where 5 represents the highest level \\
\hline & \multirow{3}{*}{ Bridging } & BRIDG1 & In the last 12 months, how often have you met with your friends and neighbors? & 1 to 5 where 5 represents the highest level \\
\hline & & BRIDG2 & How often do you talk to your friends and neighbors about agricultural issues? & 1 to 5 where 5 represents the highest level \\
\hline & & BRIDG3 & How satisfied are you with the relationship you have with your friends and neighbors? & 1 to 5 where 5 represents the highest level \\
\hline & \multirow{6}{*}{ Linking } & LINK1 & Do you belong to a cultural association? If so, how do you normally collaborate with it? & 1 to 3 where 3 represents the highest level \\
\hline & & LINK2 & Do you belong to a sports association? If so, how do you normally collaborate with it? & 1 to 3 where 3 represents the highest level \\
\hline & & LINK3 & Do you belong to a religious association? If so, how do you normally collaborate with it? & 1 to 3 where 3 represents the highest level \\
\hline & & LINK4 & Do you belong to a recreational association? If so, how do you normally collaborate with it? & 1 to 3 where 3 represents the highest level \\
\hline & & LINK5 & Do you belong to a women's or youth association? If so, how do you normally collaborate with it? & 1 to 3 where 3 represents the highest level \\
\hline & & LINK6 & Do you belong to an environmental association? If so, how do you normally collaborate with it? & 1 to 3 where 3 represents the highest level \\
\hline & \multirow{5}{*}{ Corporate } & SCS1 & In the last year, how often have you taken active part in gatherings of an agricultural/livestock cooperative? & 1 to 5 where 5 represents the highest level \\
\hline & & $\operatorname{SCS} 2$ & In the last year, how often have you taken active part in gatherings of a professional agricultural organization? & 1 to 5 where 5 represents the highest level \\
\hline & & $\operatorname{scs} 3$ & In the last year, how often have you taken active part in gatherings of an irrigation water users' association? & 1 to 5 where 5 represents the highest level \\
\hline & & $\operatorname{sCS} 4$ & In the last year, how often have you taken active part in gatherings of an 'appellation d'origine'? & 1 to 5 where 5 represents the highest level \\
\hline & & SCS 5 & To how many of the professional associations cited above do you belong to? & 0 to 4 (max value) \\
\hline \multirow{16}{*}{ 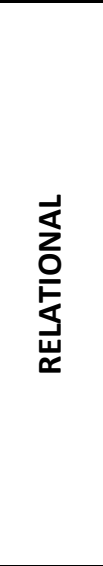 } & \multirow{3}{*}{$\begin{array}{l}\text { Knowledge- } \\
\text { Based Trust }\end{array}$} & TCKT1 & Which level of trustworthiness do you assign to your family members? & 1 to 5 where 5 represents the highest level \\
\hline & & TCKT2 & Which level of trustworthiness do you assign to your friends? & 1 to 5 where 5 represents the highest level \\
\hline & & TCKT3 & Which level of trustworthiness do you assign to the people in your village? & 1 to 5 where 5 represents the highest level \\
\hline & \multirow{3}{*}{$\begin{array}{l}\text { Trust Political } \\
\text { Institutions }\end{array}$} & TNTPI1 & Could you tell me your level of trust in your city hall? & 1 to 5 where 5 represents the highest level \\
\hline & & TNTPI2 & Could you tell me your level of trust in the regional/autonomous government? & 1 to 5 where 5 represents the highest level \\
\hline & & TNTPI3 & Could you tell me your level of trust in politicians in general? & 1 to 5 where 5 represents the highest level \\
\hline & \multirow{7}{*}{$\begin{array}{l}\text { Trust Public } \\
\text { Services }\end{array}$} & TNTPS1 & Could you tell me your level of trust in the police? & 1 to 5 where 5 represents the highest level \\
\hline & & TNTPS2 & Could you tell me your level of trust in the public health care system? & 1 to 5 where 5 represents the highest level \\
\hline & & TNTPS3 & Could you tell me your level of trust in public transport? & 1 to 5 where 5 represents the highest level \\
\hline & & TNTPS4 & Could you tell me your level of trust in the educational system? & 1 to 5 where 5 represents the highest level \\
\hline & & TNTPS5 & Could you tell me your level of trust in the court system? & 1 to 5 where 5 represents the highest level \\
\hline & & TNTPS6 & Could you tell me your level of trust in the telecommunications? & 1 to 5 where 5 represents the highest level \\
\hline & & TNTPS7 & Could you tell me your level of trust in the media? & 1 to 5 where 5 represents the highest level \\
\hline & Generalized & TNTGS1 & Generally speaking, what is your level of trust in people? & 1 to 5 where 5 represents the highest level \\
\hline & Social Trust & TNTGS2 & What level of trust do you think exists among the neighbors of your village? & 1 to 5 where 5 represents the highest level \\
\hline & Safety & SAFETY & Regarding the surrounding social environment, how safe do you think it is? & 1 to 5 where 5 represents the highest level \\
\hline
\end{tabular}


Table A1

Continued.

\begin{tabular}{|c|c|c|c|c|}
\hline $\begin{array}{l}\text { Dimen } \\
\text {-sion }\end{array}$ & $\begin{array}{l}\text { Sub-di- } \\
\text { mension }\end{array}$ & $\begin{array}{l}\text { Variable } \\
\text { Label }\end{array}$ & Description & Possible responses \\
\hline \multirow{5}{*}{ 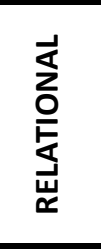 } & \multirow{2}{*}{$\begin{array}{l}\text { Tolerance } \\
\text { and Social } \\
\text { Sanction }\end{array}$} & TOLSS1 & $\begin{array}{l}\text { How much do you agree with the following statement: "If a farmer from the village does not follow the 'conditionality' } \\
\text { principle, is it fair that he receives less subsidies"? }\end{array}$ & 1 to 5 where 5 represents the highest level \\
\hline & & TOLSS2 & $\begin{array}{l}\text { How much do you agree with the following statement: "If a co-op member does not follow the co-op's rules, he/she } \\
\text { should be expelled from the coop"? }\end{array}$ & 1 to 5 where 5 represents the highest level \\
\hline & \multirow{3}{*}{$\begin{array}{l}\text { Generalized } \\
\text { Reciprocity }\end{array}$} & GENRC1 & How much do you agree with the following statement? "If I help someone, that person will help me when I need it." & 1 to 5 where 5 represents the highest level \\
\hline & & GENRC2 & How much do you agree with the following statement? "Farmers help each other in case of need or emergency." & 1 to 5 where 5 represents the highest level \\
\hline & & GENRC3 & How much do you agree with the following statement? "People in the village look after others' needs and interests." & 1 to 5 where 5 represents the highest level \\
\hline \multirow{14}{*}{ 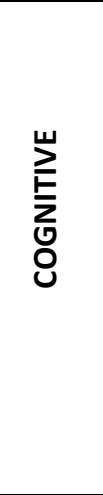 } & \multirow{4}{*}{$\begin{array}{l}\text { Community } \\
\text { Cohesiveness }\end{array}$} & COMC1 & Are there significant differences in your village regarding 'land ownership'? & 1 to 5 where 5 represents the lowest level \\
\hline & & COMC2 & Are there significant differences in your village regarding 'political party disputes'? & 1 to 5 where 5 represents the lowest level \\
\hline & & СОМС3 & Are there significant differences in your village due to 'religious' reasons? & 1 to 5 where 5 represents the lowest level \\
\hline & & COMC4 & Are there significant differences in your village because of 'ethnic' problems? & 1 to 5 where 5 represents the lowest level \\
\hline & \multirow{10}{*}{ Civicness } & CIVIC1 & How interested are you in issues related to 'agriculture and the rural world'? & 1 to 5 where 5 represents the highest level \\
\hline & & CIVIC2 & How interested are you in the development of your region? & 1 to 5 where 5 represents the highest level \\
\hline & & CIVIC3 & How interested are you in issues related to 'regional district' (i.e., county)? & 1 to 5 where 5 represents the highest level \\
\hline & & CIVIC4 & How interested are you in issues related to 'Spain'? & 1 to 5 where 5 represents the highest level \\
\hline & & CIVIC5 & How interested are you in issues related to the 'European Union'? & 1 to 5 where 5 represents the highest level \\
\hline & & CIVIC6 & How informed do you think you are about issues related to 'agriculture and the rural world'? & 1 to 5 where 5 represents the highest level \\
\hline & & CIVIC7 & How informed do you think you are about the degree of development of your region? & 1 to 5 where 5 represents the highest level \\
\hline & & CIVIC8 & How informed do you think you are about issues related to your 'regional district'? & 1 to 5 where 5 represents the highest level \\
\hline & & CIVIC9 & How informed do you think you are about issues related to 'Spain'? & 1 to 5 where 5 represents the highest level \\
\hline & & CIVIC10 & How informed do you think you are about issues related to the 'European Union'? & 1 to 5 where 5 represents the highest level \\
\hline
\end{tabular}

